\title{
Helicobacter pylori in Gastric biopsy: A Histochemical and Immunohistochemical Assessment
}

\author{
Zainab Waleed Aziz ${ }^{*}$, Shuaib Hashim Saleem** , Hatim Abdulmajeed Al-Nuaimy ${ }^{\star \star \star}$ \\ *Department of Pathology, College of Medicine, Ninevah University, Mosul, Iraq, **Department of Pathology, College of \\ Medicine, University of Mosul, Mosul, Iraq, ${ }^{\star \star \star}$ Senior Histopathology, Al-Jumhorii Teaching Hospital, Mosul, Iraq . \\ Correspondence: zainabwaleed90@yahoo.com
}

(Ann Coll Med Mosul 2019; 41 (2):139-147).

Received: $16^{\text {th }}$ Feb. 2019; Accepted: $15^{\text {th }}$ May 2019.

\begin{abstract}
Background: Helicobacter species pylori represent one of the medically prominent and most common infections in the world. Contamination with this microbe has set as a causal factor in the development of gastritis, peptic ulcer, and gastric neoplasia. Consequently, prompt diagnosis is essential.

Objectives: This study was conveyed to detect H.pylori in gastric biopsies specimens by using routine Hematoxylin, Modified Giemsa dye as well as immunohistochemical stain, besides to assess the specificity and sensitivity of Helicobacter microbe detection in each method.

Patients and methods: The research was both prospective and retrospective, carried out on 100 cases of endoscopically obtained gastric biopsies. Data obtained from archives of the pathology department, at AL-Jamhuri Teaching Hospital, Mosul city, and collected in a period spanning from April 2013 to March 2014. The information included; Age, sex, gastric biopsy location, inflammation status, the presence of dysplasia or carcinoma. Helicobacter pylori infection was assessed histochemically and immunohistochemically.

Results: In a total of 100 gastric samples, patients' age range was 11 to 82 years (mean age of 46.5 years), with a male to female ratio of 1.38:1. Helicobacter pylori bacilli were positive with H\&E/MGS in $71(71 \%)$ of cases, increased to $75(75 \%)$ case with IHC. Chronic gastritis noticed in 85 biopsy specimens, $74 \%$ were positive for H.pylori. There was a statistically significant difference between IHC and H\&E/MGS $(p=0.04)$ for detection of H.pylori. The sensibility and specificity of the H\&E/MGS were measured compared with the recommended standard sensitive and specific $\mathrm{IHC}$ test; they were $95 \%$ and $100 \%$ respectively.

Conclusion: The routine ancillary stains request for the detection of H.pylori remains a laboratory and an institution right. This study revealed that, in our laboratory, the regular application of ancillary dyes is not obliged for the description of H.pylori because it was readily recognizable in the bulk of sections with haematoxylin staining. However, we recommend the use of IHC in specific circumstances.
\end{abstract}

Keywords: Helicobacter pylori, Gastric biopsy, Modified Giemsa stain, Immunohistochemistry, Cancer.

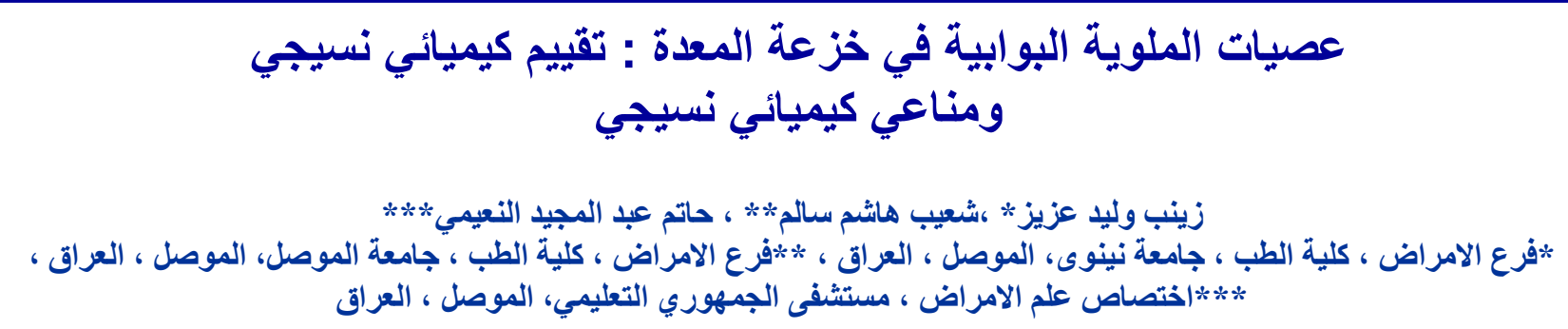

الخلاصة

معلومات أساسية: عصيات الملوية البو ابية تمثل واحدة من الأمر اض الأكثر شيو عاً في جميع أنحاء العالم. العدوى بهذه البكتيريا

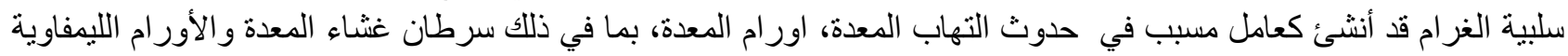


لأنسجة المعدة المرتبطة بالغشاء المخاطي .ولهذا بالنظر إلى الآثار الموثقة توثيقاً جيدا من ناحية الأمراض التي تسببها هذه

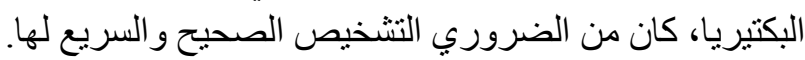
الهاف من الدراسة: أجريت هذه الدراسة للكثف عن بكتيريا الملوية البوابية باستخدام ثلاثة أساليب: صبغة روتينية ، صبغة خاصة وكذلك طريقة مناعيةـ كيميائيةـ نسيجية في خزعات الكية المعدة. لقد جمعت العينات من مختلف الحالات المرضية للمعدة وقد

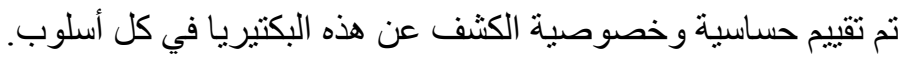

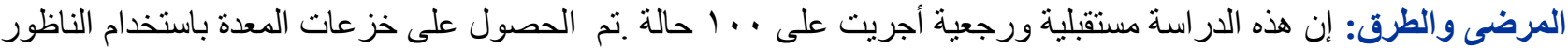

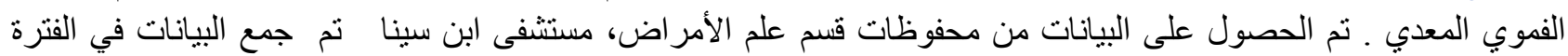

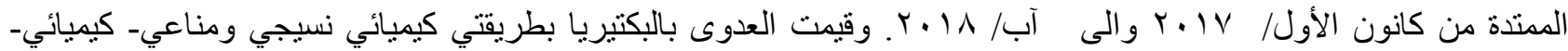

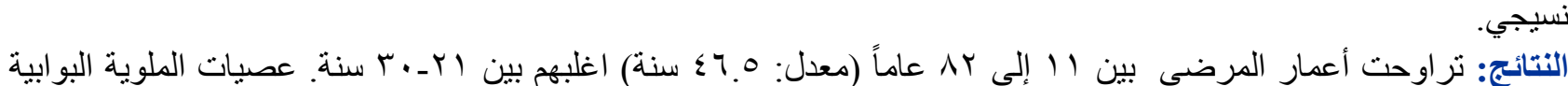

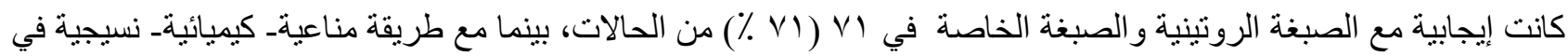

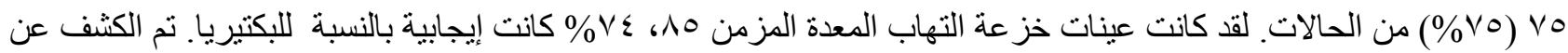

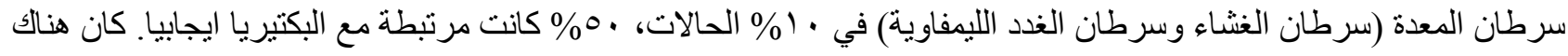

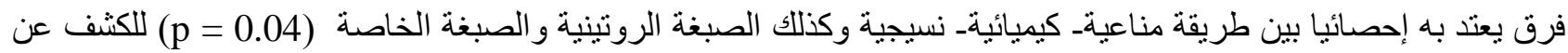

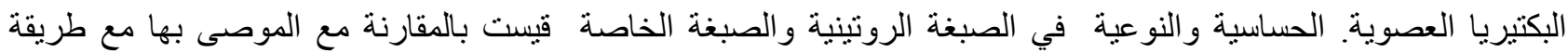

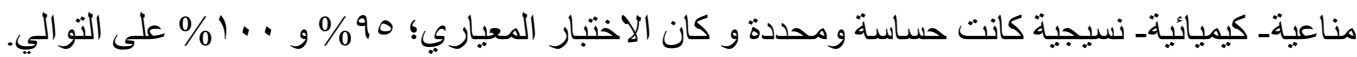

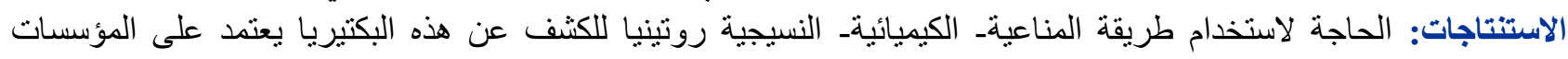

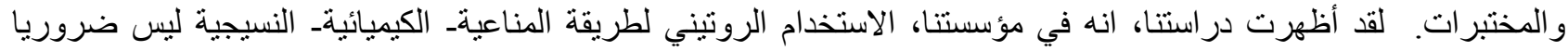

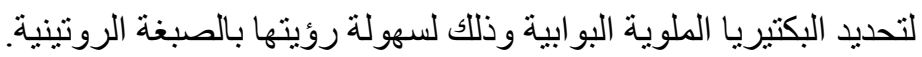

الكلمات المفتاحية: عصيات الملوية البو ابية، خز عة المعدة، صبغة كيمزا المعدلة، الطريقة المناعية_الكيميائية_النسيجية، سرطان .

\section{INTRODUCTION}

elicobacter pylori (H. pylori) represent one of the medically prominent and most common infections worldwide ${ }^{1}$. It is a curved rod gramnegative multi-flagellated bacterium observed virtually solely attached on the gastric mucosa of human beings ${ }^{2}$. Under unfavorable circumstances, it can become viable but non-culturable coccoid form ${ }^{2}$. In gastric biopsies, Helicobacter microbes are 0.5 to $1.0 \mathrm{Mm}$ wide and 2.5 to $5.0 \mathrm{Mm}$ long; they carry up to six unipolar wrapped flagella which are crucial for bacterial movement ${ }^{3}$. Flagella manifests a specific end bulb, which is an expansion of the flagellar case ${ }^{3}$. In developing countries, $70 \%$ to $90 \%$ of the people carries $\mathrm{H}$. pylori before the age of 10 years ${ }^{3}$. In developed countries, the prevalence of infection is lower, varying from $25 \%$ to $50 \%{ }^{4}$. The rate of new $\mathrm{H}$. pylori infections among adults in the Westerly world is less than $0.5 \%$ per year ${ }^{5}$. Since spontaneous elimination of the infection is rare, it proceeds in most cases to chronic gastritis ${ }^{6,7}$. However, the cytokine response and the gastric acid secretion are bound for an individual's ultimate clinical outcome ${ }^{8}$. It has found that a reduction in the production of gastric acid predisposes to corpus gastritis or pangastritis which in turn leads to gastric ulcer, atrophy, and carcinoma ${ }^{9,10}$.

In gastric cancer, irrespective of their histology, most of these tumors originate from mucosa infected by $H$. pylori and very rarely occur without inflammation. Therefore, $\mathrm{H}$. pylori are considered to be a strong factor in the evolution of gastric cancer ${ }^{11,12}$.

Therefore, regarding all facts about the strong correlation between $H$. pylori and different upper gastrointestinal lesions, it is very crucial to specify the presence of this bacteria in gastric biopsy reports as it has an important role in the therapeutic implications too ${ }^{13}$. Since, over years pathologists have sought different reliable methods for detecting $H$. pylori in biopsy specimens, including special stains, immunohistochemistry (IHC), polymerase chain reaction (PCR) and lately, in situ hybridization ${ }^{14}$. 


\section{PATIENTS AND METHODS}

\section{Patient Selection}

This study was a prospective and retrospective carried out in a series of 100 consecutive endoscopically obtained gastric biopsies during a period spanning from April 2013 to March 2014. A tissue block of each case was chosen for histochemistry and IHC.

We maintained a routine protocol approval to access the clinicopathological data from archives of the department of pathology laboratory, at ALJamhurii Teaching Hospital, Mosul City, and these included; Age (ranged from 11 to 82 years with a mean of 46.5 years), sex (58 males and 42 females with a male to female ratio of $1.38: 1$ ), gastric biopsy location .

Patients with chronic gastritis, gastric ulcers, adenocarcinoma, and MALToma also included.

The studied cases of chronic gastritis were reviewed according to the recommended table by the Sydney system ${ }^{15}$.

\section{Histochemical and IHC Staining}

All the obtained gastric biopsies were collected, placed on filter paper, fixed in 10\% formalin overnight, processed, and embedded in paraffin wax. After that 4 micron-thick tissue sections taken.

Once the slides prepared, $\mathrm{H}$. pylori status analyzed by three methods: H\&E, modified Giemsa stain (MGS) using 1:9 dilution (Sheehan's modified may) and immunohistochemical stains (IHC) applying a rabbit polyclonal antibody against H. pylori (1:160 dilution; Cell Marque, Ventana, catalog: 760-2645, Rocklin, Calif) according to the manufacturer's guidance using automated BenchMark instrument (Ventana). Antigen retrieval was performed by microwave heating in a sodium citrate buffer. An avidin-biotin detection method used with 3,39-diaminobenzidine tetrahydrochloride visualization ${ }^{16}$.

\section{Scoring and Analysis of H.pylori Staining}

All cases microscopically examined for interpretation of histochemical and immunohistochemical stains of $H$ pylori infection. Each set of histologic sections calculated, and the results inscribed.

H.pylori categorized as either positive or negative. The presence of any stained organisms resembling H.pylori bacteria designated as positive. The lack of any $H$. pylori like microbe stain assigned as negative. $H$. pylori is typically a curved rod microbe that is $2.5-4.0$ microns long and $0.5-1.0$ microns thick. It is observed on the lumen or epithelial surface of the gastric mucosa; the organisms are infrequently seen in within epithelial cells or gastric crypts ${ }^{17}$.

\section{Statistical Analysis}

The Chi-square test was performed to analyze negative and positive cases as defined by $\mathrm{H} \& \mathrm{E} / \mathrm{MGS}$ and IHC for pathologic hallmarks. A cut level of $p<0.05$ was used for separation of cases.

\section{RESULTS}

The patients' age range was 11 to 82 years (mean of 46.5 years) most of them were in the third decade. There were 58 (58\%) males and 42 $(42 \%)$ females with a male to female ratio of 1.38:1, Figure 1\&2 .

The presence of $H$. pylori was significantly correlated with male sex and with young age group $(\mathrm{p}<00.1)$, as shown in Table 1 .

Gastric biopsies were obtained from the antrum $(81 \%)$ and the corpus (19\%) only. The frequency of $H$. pylori was higher in the antrum than corpus both histochemically and immunohistochemically, Table 2 .

The histopathological findings of endoscopically obtained gastric biopsies were all illustrated in Table 3 . Cases of gastritis were classified and graded, according to the updated Sydney system, Table 4 .

The detection rate of $H$. pylori was different with different stains used (H\&E, MGS or $\mathrm{IHC}$ ). The bacilli were positive with H\&E/MGS in $71(71 \%)$ of cases, increased to 75 (75\%) by IHC stain, with a degree of colonization graded into mild, moderate and marked, Table 5 \& Figure 3 . There were 8 $(11 \%)$ cases of mild colonization detected by IHC; of these 8 cases, only 4 were positive by the H\&E/MGS Figure 4\&5. On the other hand, all moderate and marked cases were positive by all stains, Figure $\mathbf{3} \mathbf{6} \mathbf{6}$. All parenchyma infected with $H$. pylori manifested variable active and chronic gastritis. With a sample of 85 chronic gastritis biopsy specimens, 63 (74\%) maintained active inflammation, and 22 (26\%) kept chronic inactive inflammation. The presence of $H$. pylori significantly linked with active $(p<0.0001)$ and chronic $(p<0.0001)$ inflammation. Among $H$. pylori 
definite chronic gastritis, there was no significant difference between the infiltration of $H$. pylori in the mucosa and the degree of severity (mild, moderate, or severe). Intestinal metaplasia was present in $3(4 \%)$ cases of gastritis; one was of a severe type. Two of them were positive for Helicobacter microbe by $\mathrm{IHC}$; both displayed colonization of bacteria in areas other than metaplasia. Five gastric biopsies exhibited features of peptic ulcer, $H$. pylori were positive in 3 of them. Gastric cancer (adenocarcinoma and lymphoma) detected in $10 \%$ of the cases, $50 \%$ were associated with $\mathrm{H}$. pylori positivity. The presence of $H$. pylori significantly correlated with dysplasia and gastric cancer in spite of the small sample in this study $(p<0.04)$. Figure 7 .

The sensitivity and specificity of the H\&E/MGS were measured compared with the recommended standard sensitive and specific $\mathrm{IHC}$ test; they were $95 \%$ and $100 \%$ respectively. Ultimately, this survey noticed a statistically significant difference between IHC and H\&E/MGS $(p=0.04)$ for the detection of H. pylori.

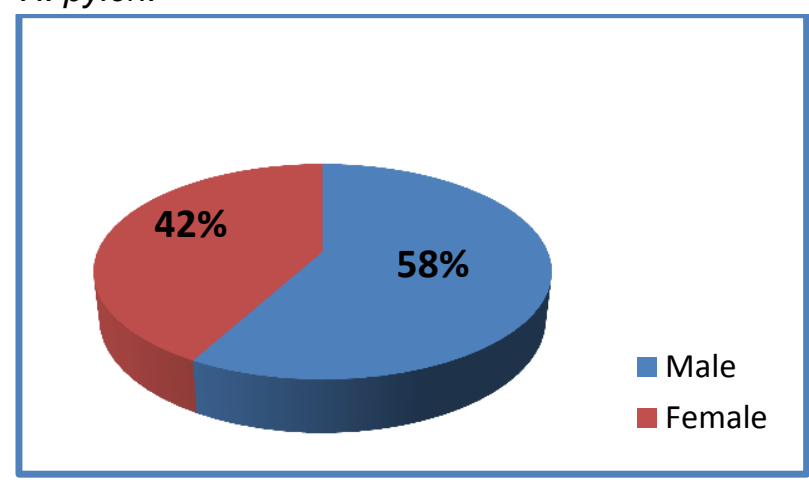

Figure 1: Sex distribution .

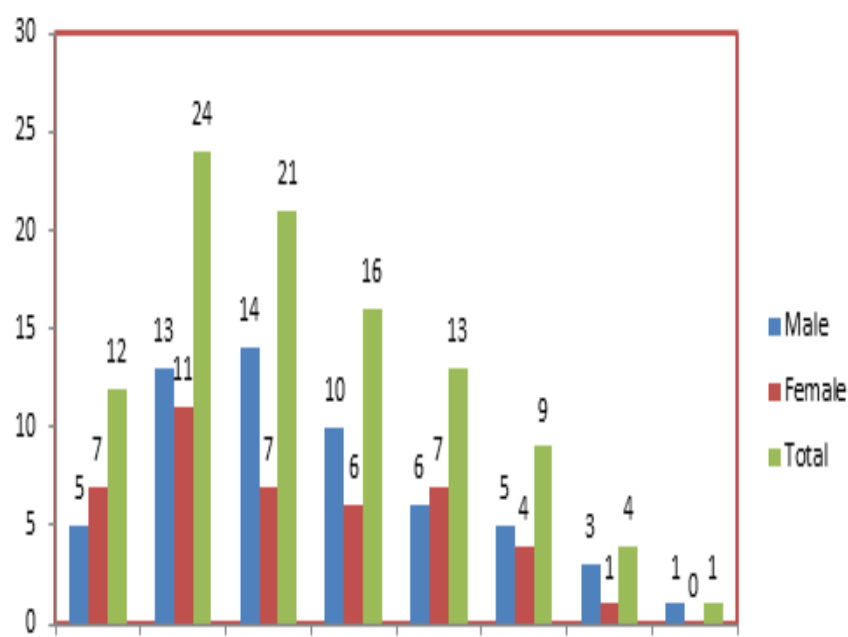

$11-20$ yr $21-30$ yr. $31-40$ yr. $41-50$ yr. $51-60$ yr. 61.70 yr. $71-80$ yr. $>800$ yr.
Table 1: H. pylori density in relation to age and sex in the study group.

\begin{tabular}{lcccccc}
\hline H pylori & $\begin{array}{l}\text { Age } \\
\leq 40\end{array}$ & $\begin{array}{l}\text { Age } \\
>40\end{array}$ & Male & Female & Total \\
\hline Positive & 43 & 28 & 38 & 33 & 71 \\
\hline Negative & 14 & 15 & 20 & 9 & 29 \\
\hline Total & 57 & 43 & 58 & 42 & 100 \\
\hline
\end{tabular}

$p$ value $<0.01$.

Table 2: Correlation between histochemistry and IHC for detection of H.pylori in relation to the location of the gastric biopsy.

\begin{tabular}{cccc}
\hline $\begin{array}{c}\text { H. pylori } \\
\text { presence }\end{array}$ & $\begin{array}{c}\text { Corpus } \\
(\mathrm{n}=19)\end{array}$ & $\begin{array}{c}\text { Antrum } \\
(\mathrm{n}=81)\end{array}$ & $\begin{array}{c}\text { Total } \\
(\mathrm{n}=100)\end{array}$ \\
\hline $\begin{array}{c}\text { Histochemistry } \\
\text { Positive }\end{array}$ & 11 & 60 & 71 \\
Negative & 8 & 21 & 29 \\
IHC & & & \\
Positive & 12 & 63 & 75 \\
Negative & 6 & 19 & 25 \\
\hline
\end{tabular}

Table 3: Histopathological findings of endoscopically obtained gastric biopsies.

\begin{tabular}{lc}
\hline Histopathological findings & $(\mathrm{n})$ \\
\hline Chronic gastritis & 85 \\
& \\
\hline Gastric ulcer & 5 \\
\hline Gastric cancer & 10 \\
Adenocarcinoma & 7 \\
Intestinal type & 3 \\
Diffuse type & 4 \\
Lymphoma(MALToma) & 3 \\
\hline Total & 100 \\
\hline
\end{tabular}

Figure 2: Age and sex distribution 
Table 4: H.pylori colonization and histological grades of gastritis by updated Sydney system.

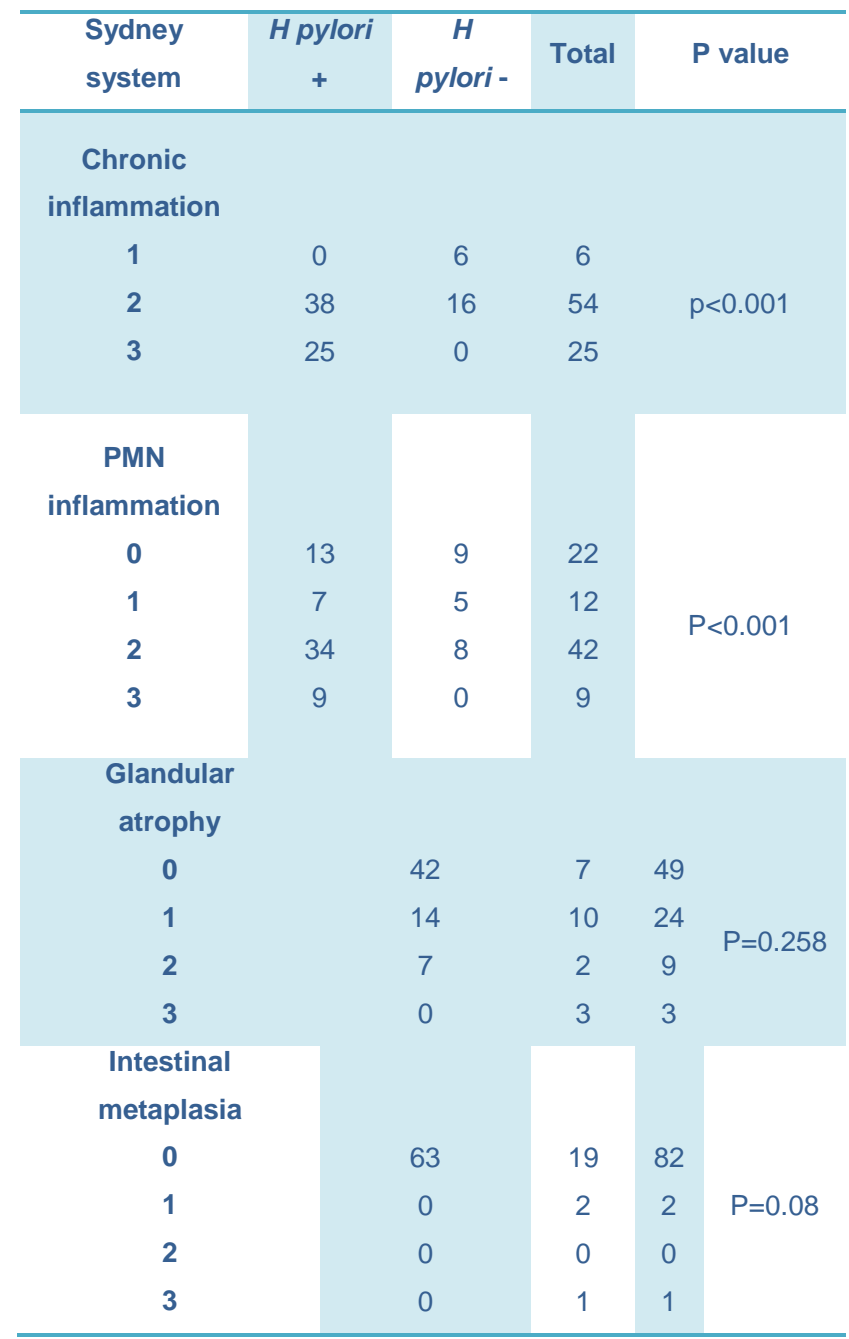

Table 5: H.pylori colonization in correlation to histochemistry and IHC

\begin{tabular}{lll}
\hline H. pylori colonization & H\&E/MGS (n) & IHC (n) \\
\hline 0 None & 29 & 25 \\
\hline Mild & 4 & 8 \\
\hline Moderate & 41 & 41 \\
\hline Severe & 26 & 26 \\
\hline Total & 100 & 100 \\
\hline
\end{tabular}

$p$ value $=0.04$
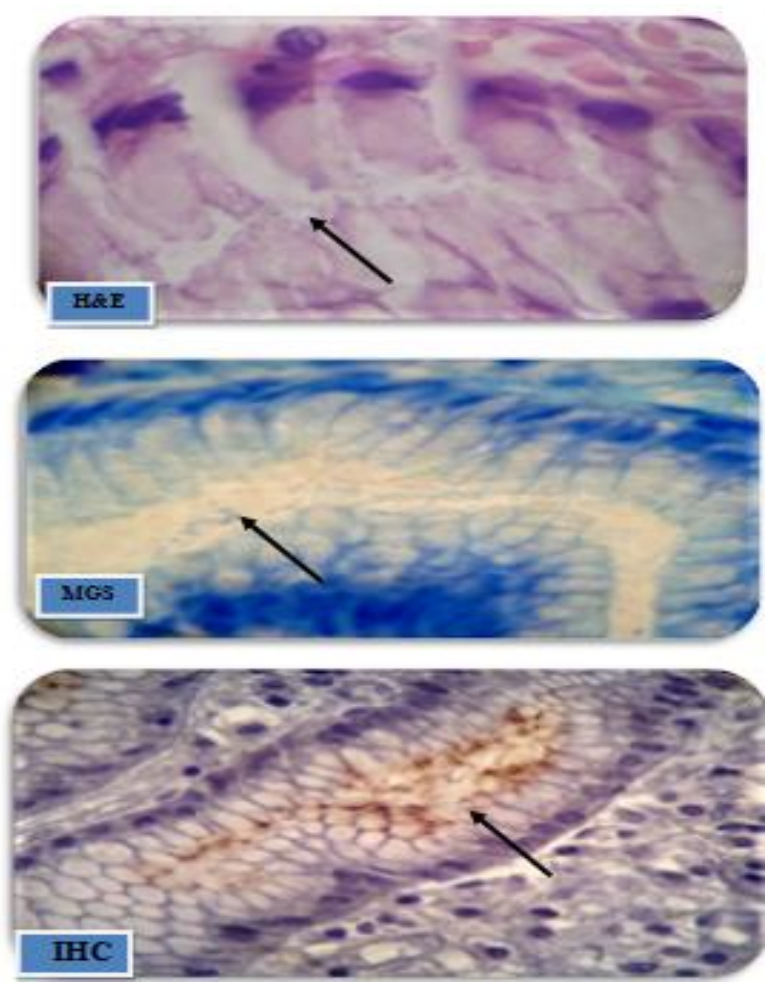

Figure 3: The typical spiral curved $H$. pylori bacterium can be clearly seen using the three staining methods. (100X oil objective).
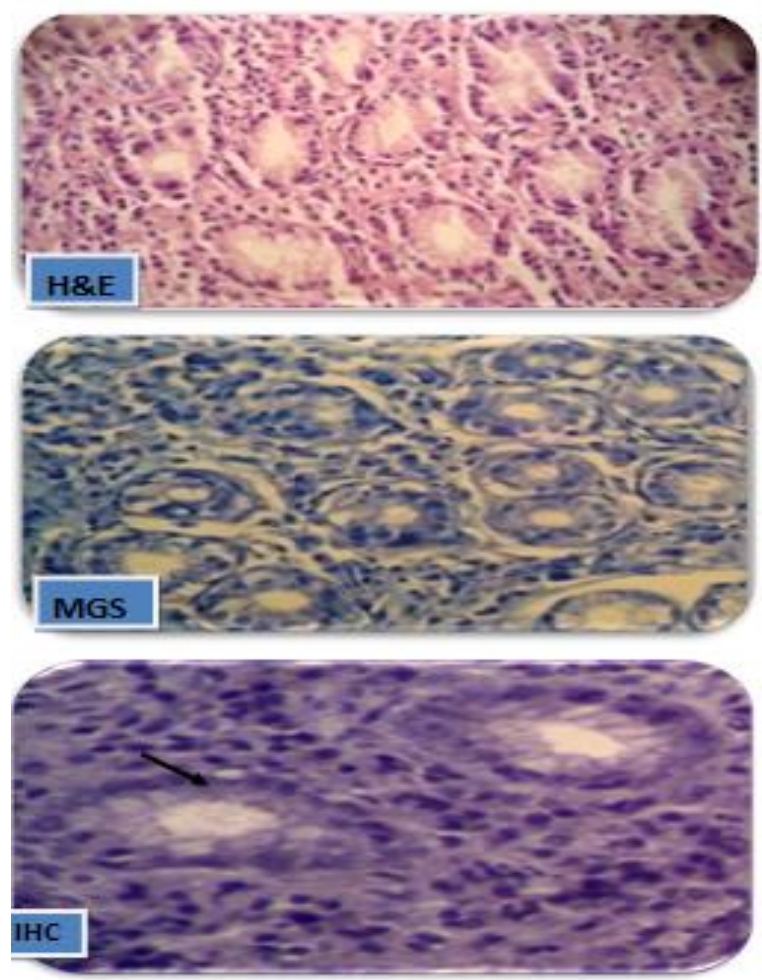

Figure 4: Chronic gastritis with H\&E/MGS negative for $H$. pylori; however, IHC was positive for the coccoid form( arrow), (10×40HPF). 

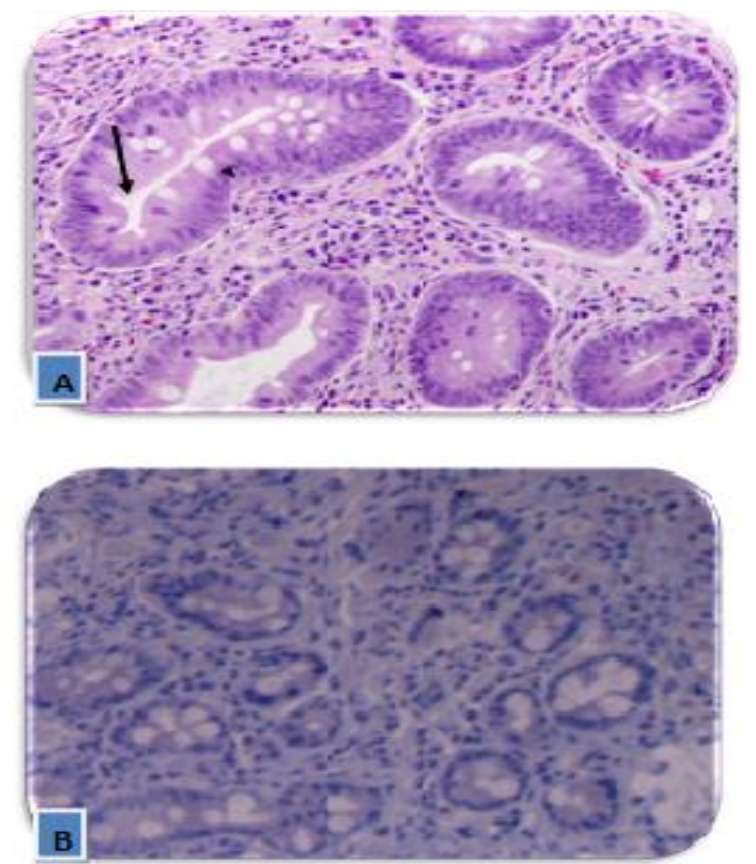

Figure 5: (A, arrow), chronic gastritis with intestinal metaplasia and small cylindrical structures "suspicious" for Helicobacter pylori seen with H\&E staining; $(B)$, however, the immunohistochemical stain was negative, .$(10 \times 10 \mathrm{HPF})$.
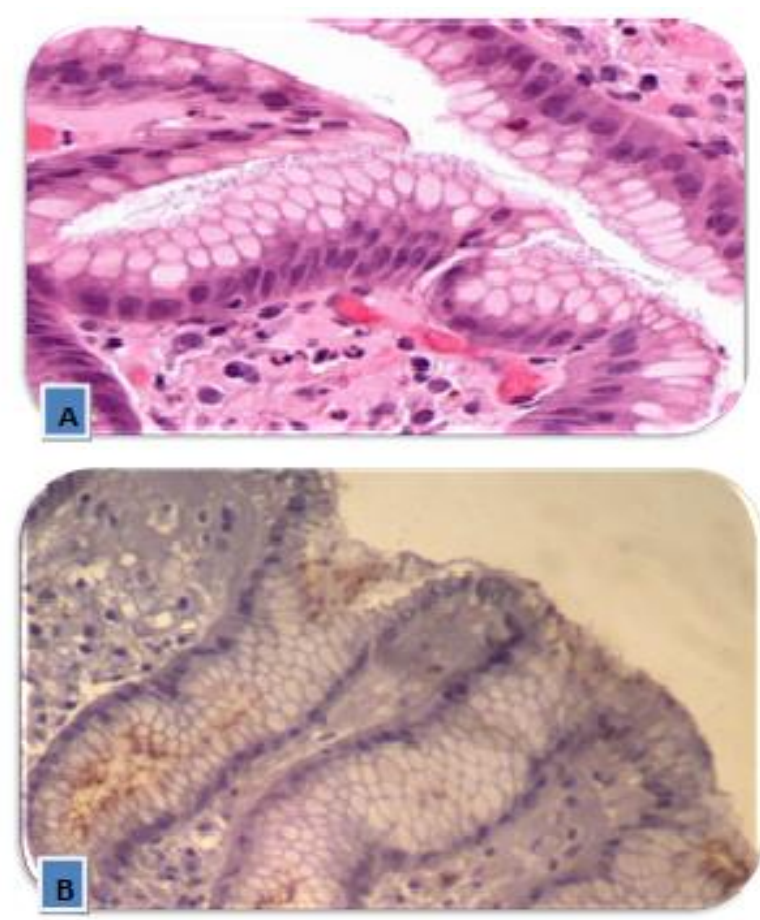

Figure (6): (A),Chronic active gastritis with abundant organisms on the surface; (B),confirmed by immunohistochemical staining.$(10 \times 10 \mathrm{HPF})$.

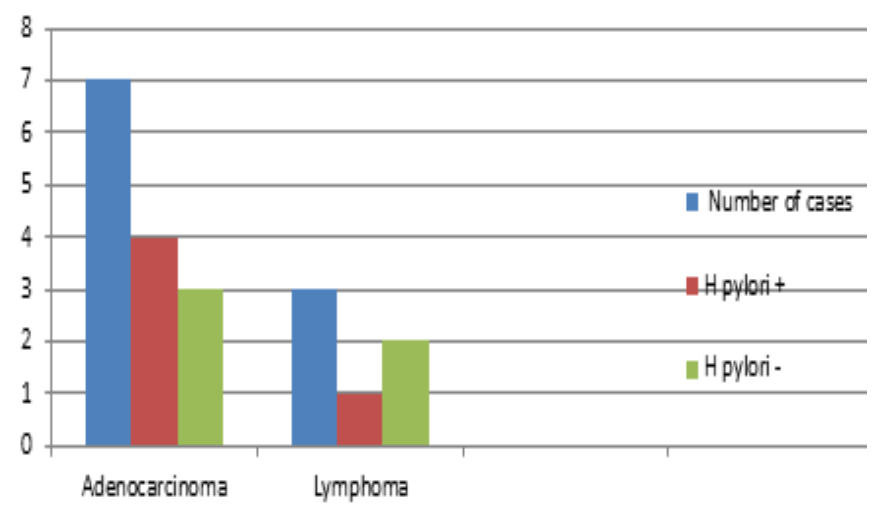

Figure 7: Association of $H$. pylori with gastric cancer. ( $p$ value $<0.04$ )

\section{DISCUSSION}

Helicobacter pylorus is a major human pathogen for which an accurate detection required for proper patient management ${ }^{18}$. In most cases, H.pylori recognized in a good hematoxylin and eosin stain. However, the sensitivity of this remains low, especially when there are no many bacteria ${ }^{18}$. None one method has sufficient sensitivity and specificity to be considered a gold standard, therefore, most laboratories use an additional staining method in the identification of the organism $^{14,18}$.

In the present study, we adopted three methods (H\&E, MGS, and IHC) for $H$. pylori revealing. The mean age of sampled patients was 46.5 years, being more prevalent between 21 and 30 years. The $H$. pylori appearance significantly correlated with a young age group, a finding similar to the fact that the incidence of $H$. pylori infection is higher at a younger age in the developing world ${ }^{19}$.

This study displayed H.pylori infection more common in male sex which is similar to a systematic review and meta-analysis of 244 studies analyzed by lbrahim et $\mathrm{al}^{20}$. The result of this study perhaps attributed to some male habits like smoking, alcohol drinking, and diet-related factors that might damage gastric mucosa and change the gastric internal environment.

Similar to our research, most studies confirmed the high prevalence rate of antral H.pylori, utilizing various identification methods ${ }^{5}$, this explained by that, in practice, most gastric biopsies obtained from the antrum.

The detection rate of $H$ pylori is variable and dependent on the stain used ( H\&E, special stain 
or $\mathrm{IHC}$ ). It has reported that hematoxylin-eosin stain alone can detect $H$. pylori in $66 \%$ of cases with many false positives and false negatives ${ }^{18}$.

In this study, we introduced a modified Giemsa stain (MGS) and immunohistochemistry (IHC) stain for detection of $H$. pylori. The bacilli were positive with H\&E/MGS in 71 ( $71 \%)$ of cases this rate increased to $75 \%$ by using IHC. The sensibility and specificity of the H\&E/MGS were measured compared with the recommended standard sensitive and specific IHC test; they were $95 \%$ and $100 \%$ respectively. This high sensitivity attributed to patient used during the examination of the H\&E and Giemsa stained sections in addition to the use of at least 15 high power fields looking for $H$. pylori organisms, a similar finding reported in Smith et $\mathrm{al}^{21}$.

However, the false negative results in H\&E/MGS explained by the fact that the mildly colonized or the singly scattered bacteria easily be lost by the $\mathrm{H} \& \mathrm{E} / \mathrm{MGS}^{22}$. In extension to the point that many $H$. pylori organisms transformed into coccoid forms, after therapy, which may pass by the routine dyes undetected $^{22}$. Those single or modified organisms were visualized obviously by $\mathrm{IHC}{ }^{(22,23)}$. Based on these results it is clear that immunohistochemical staining could marginally enhance the detection rate of the organisms ${ }^{23}$.

In the current research with an 85 chronic gastritis biopsy samples, the significant association between chronic active gastritis and $H$. pylori infection has been previously analyzed in many other studies ${ }^{24,25}$. Hence, the chronic active inflammation should prompt a careful search of the sections for the presence of the H. pylori.

Five percent of dyspeptic patients confirmed to have gastric ulcer disease in this study, three of them were positive for $H$. pylori microbe, a conclusion that similar to a study in Iran, with a percentage of $71 \%{ }^{26}$.

Chronic $H$. pylori gastritis leads in more than half of the affected subjects to gastric atrophy ${ }^{27}$. In this survey, glandular atrophy present in 36 (42.4\%) cases of chronic gastritis, most were of a mild degree, results similar to those reported by previous studies done in $\operatorname{Iraq}^{8,28}$. On the other hand, $H$. pylori were present in $49.5 \%$ of atrophic gastritis just comparable to those reported in Turkey and Iran, (43\% and 68\%) respectively ${ }^{29,26 .}$
Despite some doubts, it globally believed that $H$. pylori have a fundamental role in the pathogenesis of gastric cancer ${ }^{30}$. Gastric cancer (adenocarcinoma and lymphoma) detected in 10\% of the studied sample, $50 \%$ were associated with $H$. pylori similar to Taiwanese study ${ }^{31}$. The residence of Helicobacter microbe was positively associated with gastric dysplasia and cancer in spite of the small sample. However, further studies are needed to confirm the role of this microorganism in the gastric carcinogenesis in our locality.

The results of this study revealed that $\mathrm{IHC}$ is a highly specific and sensitive method for the identification of $H$. pylori as compared to H\&E and MGS $^{2}$. However, in our laboratory, $H$. Pylori almost readily viewed in the majority of cases with haematoxylin stain which comparable to a recent study suggesting that pathologists' are able to identify these bacilli regardless their training level therefore ancillary staining for $H$. pylori is not indicated in our practice ${ }^{32}$. However, in a small number of cases, an immunohistochemical stain can be particularly useful like in severe active gastritis in which no helicobacter microbes could be detected on haematoxylin stains, to avoid the false-negative results, and for the follow-up biopsies to confirm the absence of $H$. pylori regardless of the number of the organisms present or the shape it chooses ${ }^{2}$.

\section{CONCLUSION}

The routine ancillary stains request for the detection of $H$. pylori remains a laboratory and an institution right. This study revealed, in our laboratory, a regular application of ancillary dyes for the description of $H$. pylori not obligated because it was readily recognizable in the bulk of sections with haematoxylin staining. However, we propose IHC for samples with severe chronic severe active gastritis in which $H$. pylori not distinguished by H\&E dyes, post-treatment biopsy samples, and when particles "suspicious" but not conclusive for $H$. pylori viewed on haematoxylin stains. 


\section{REFERENCES}

1.Sarma A, Hazarika BB, Patgiri SJ, et al. Isolation of Helicobacter pylori from Gastric Biopsy Specimens and Evaluation of Common Contaminants Associated with $\mathrm{H}$. Pylori Cultures. Int J Med Res Prof. 2016; 2; 161-4.

2. Mégraud $F$ and Lehours $P$. Helicobacter pylori Detection and Antimicrobial Susceptibility Testing. Clin. Microbiol. Rev. 2007; 20: 280-322.

3. Amieva MR, El-Omar EM. Host-bacterial interactions in Helicobacter pylori infection. Gastroenterol. 2008;134(1):306-23.

4. Horvitz G and Gold BD. Gastroduodenal diseases of childhood. Curr. Opin. Gastroenterol, 2006; 22:632-40.

5.Kusters $J$, van Vliet $A$, Kuipers $E$, et al . Pathogenesis of Helicobacter pylori infection. Clin. Microbiol. Rev. 2006; 19:449-90.

6. Valle K, Kekki E, Sipponen R, et al. Long-term course and consequences of Helicobacter pylori gastritis. Results of a 32-year follow-up study. Scand. J. Gastroenterol. 1996; 31: 546-50.

7. Kosunen TU, Aromaa A, Knekt $\mathrm{P}$, et al. Helicobacter antibodies in 1973 and 1994 in the adult population of Vammala, Finland. Epidemiol. Infect.1997; 119:29-34.

8. Hussein NF, Napaki SM, Atherton JC, et al. A Study of Helicobacter pylori-associated Gastritis Patterns in Iraq and Their Association with Strain Virulence. Saudi J Gastro. 2009; 15: 125-7

9.Lochhead P and El-Omar E. Helicobacter pylori infection and gastric cancer. Baillieres Best Pract. Res. Clin. Gastroenterol. 2007; 21:281-97.

10. Rugge MP, Correa M, Dixon F, et al. Gastric mucosal atrophy: interobserver consistency using new criteria for classification and grading. Aliment. Pharmacol. Ther. 2005; 16:1249-59.

11. Asaka M, Kato M, Graham DY, et al. Prevention of Gastric Cancer by Helicobacter pylori Eradication. Inter Med. 2010; 49: 633-6.

12. Lee JU and Kim N. Diagnosis of Helicobacter pylori by invasive test: histology. Ann Transl Med. 2015;3: 1-10.

13. Wong BC, Lam SK, Wong WM, et al. Helicobacter pylori eradication to prevent gastric cancer in a high-risk region of China: a randomized controlled trial. JAMA 2004; 291:187-94.
14. Patnayak R, Reddy V, Jena A, et al. Utility of immunohistochemistry in demonstrating Helicobacter pylori. Onc Gas Hep Rep. 2015;4:47

15. Dixon MF, Genta RM, Yardley JH, et al. Classification and grading of gastritis. The updated Sydney system. Am J Surg Pathol 1996;20:1161-81.

16. Guesdon J, Ternynck T, Avrameas S, et al. The use of avidin-biotin interaction in immunoenzymatic techniques. J Histochem Cytochem. 1979; 27:1131-9.

17. Riba AK, Ingeneri $\mathrm{TJ}$, Strand $\mathrm{CL}$, et al. Improved Histologic Identification of Helicobacter pylori by Immunohistochemistry Using a New Novocastra Monoclonal Antibody. Laboratory Medicine. 2011;42:35-9.

18. El-Zimaity $\mathrm{H}$, Graham $\mathrm{D}$, Al-Assi $\mathrm{M}$, et al. Interobserver variation in the histopathological assessment of Helicobacter pylori gastritis. Hum Pathol. 1996; 27:35-41.

19. Khalifa MM, Sharaf RR, Aziz1 RK, et al. Helicobacter pylori: a poor man's gut pathogen? Gut Pathogens. 2010;2:2.

20. Ibrahim A, Morais S, Ferro A, et al. Sexdifferences in the prevalence of Helicobacter pylori infection in pediatric and adult populations: Systematic review and meta-analysis of 244 studies. Dig Liver Dis. 2017; 49(7):742-9

21. Smith SB, Snow AN, Perry RL, et al. Helicobacter pylori To Stain or Not to Stain? Am J Clin Pathol. 2012;137:733-8.

22. Marzio L, Angelucci D, Grossi L, et al. AntiHelicobacter pylori specific antibody immunohistochemistry improves the diagnostic accuracy of Helicobacter pylori in biopsy specimen from patients treated with triple therapy. Am J Gastroenterol. 1998;93:223-6

23. Ayoola AE, Ageely HM, Gadour MO, et al . Prevalence of Helicobacter pylori infection among patients with dyspepsia in South-Western Saudi Arabia. Saudi Med J 2004; 25: 1433-8

24. Pranjal Sharma R, Kalpana Kumari MK. Histological identification of Helicobacter pylori : comparison of staining methods. Int $\mathrm{J}$ Med Res Rev. 2015;3(10):1167-73

25. Gunaid A, Hassan N, Murray-Lyon I, et al. Prevalence and risk factors for Helicobacter pylori infection among Yemeni dyspeptic patients. Saudi Med J 2003; 24: 512-7 
26. Hashemi M.R, Rahnavardi M, Bikdeli B, et al. $H$ pylori infection among 1000 southern Iranian dyspeptic patients. World J Gastroenterol. 2006; 34: $5479-82$

27. Zhang C, Yamada N, Wu YL, et al. Helicobacter pylori infection, glandular atrophy and intestinal metaplasia in superficial gastritis, gastric erosion, erosive gastritis, gastric ulcer and early gastric cancer. World J Gastroenterol. 2005;11(6):791-6.

28. Ahmed A M. Histopathological evaluation of chronic gastritis in Duhok region according to the updated Sydney system. A thesis submitted to the scientific council of pathology in partial fulfillment of the requirement for the degree of fellowship in the Iraqi board for medical specialization in pathology,2010.

29. Fikret D, Kaya Ö, Suna E, et al. Relationship between atrophic gastritis, intestinal metaplasia, dysplasia and Helicobacter pylori infection. Turkish J Gastroenterol. 2001;12:169-72

30. Singh K, Ghoshal UC. Causal role of Helicobacter pylori infection in gastric cancer: an Asian enigma. World J Gastroenterol. 2006; 12: 1346-51

31. Wu MS, Shun CT, Lee WC, et al. Gastric cancer risk in relation to Helicobacter pylori infection and subtypes of intestinal metaplasia. Br J Cancer. 1998;78(1): 125-8

32. Richard $\mathrm{H}$ and Robert $\mathrm{M}$. Routine AntiHelicobacter Immunohistochemical Staining is Significantly Superior to Reflex Staining Protocols for the Detection of Helicobacter in Gastric Biopsy Specimens. Helicobacter. 2016; 21,581-5. 